\title{
Behavior of Technetium in Supercritical Water: Distribution to Liquid, Solid Phases and onto Metal Surfaces
}

\author{
T. Yamamura, ${ }^{*, a}$ I. Satoh, ${ }^{a}$ N. Okuyama, ${ }^{\text {a }}$ Y. Shiokawa, ${ }^{\text {a }}$ T. Sekine, ${ }^{\text {b }}$ W. Sugiyama, ${ }^{c}$ K.-C. Park, ${ }^{d}$ \\ and H. Tomiyasu ${ }^{\mathrm{d}}$ \\ ${ }^{a}$ Institute for Materials Research, Tohoku University, Sendai, Miyagi 980-8577, Japan \\ ${ }^{\mathrm{b}}$ Department of Chemistry, Faculty of Science, Tohoku University, Sendai, Miyagi 980-8578, Japan \\ ${ }^{\mathrm{c}}$ Electric Power Research and Development Center, Chubu Electric Power Co., Inc., Kitasekiyama, Odaka-cho, \\ Midori-ku, Nagoya 459-8522, Japan \\ ${ }^{\mathrm{d}}$ Department of Chemistry and Material Engineering, Faculty of Engineering, Shinshu University, Wakasato, \\ Nagano 380-8553, Japan
}

\section{Received: July 31, 2005; In Final Form: September 30, 2005}

\begin{abstract}
The distributions of technetium among solid, liquid and gas phases in supercritical water reactions were investigated for the decomposition process of nonflammable plastic materials contaminated with technetium. In addition to supercritical water (SCW) methods with or without $\mathrm{H}_{2} \mathrm{O}_{2}$ which have been investigated extensively for decomposition method for the plastics, $\mathrm{SCW}$ with $\mathrm{RuO}_{2}$, developed by us, characteristic of reductive reaction was investigated for technetium distributions. The distributions of technetium were determined by using ${ }^{95 \mathrm{~m}} \mathrm{Tc}$ tracer with or without its carrier ${ }^{99} \mathrm{Tc}$. The gases produced during the decomposition of the organic material contain no radioactivity under all conditions in this study. Also, technetium shows a tendency to transfer to solid phase but not to liquid phase in $\mathrm{SCW}$ with $\mathrm{RuO}_{2}$. These results indicate that this process is suggested as a predominant candidate for the treatment of nonflammable organic materials in low-level radioactive wastes (LLW).
\end{abstract}

\section{Introduction}

Above $647 \mathrm{~K}$ and $22 \mathrm{MPa}$, water is a supercritical fluid, which possesses unique solvating and transport properties compared to liquids or gases. Supercritical water (SCW), which shows liquid-like density and gas-like diffusivity, has the ability not only to dissolve materials soluble in liquid water but also to promote particular reaction. Using the supercritical water, gasification of organic materials using $\mathrm{RuO}_{2}$ as a catalyst has been developed. ${ }^{1}$ We applied this gasification method to the decomposition of bulky non-flammable organic materials generated in nuclear power plants, classified as low-level radioactive wastes (LLW). ${ }^{2,3}$ Radioactive iron, cobalt, cesium, iodine, strontium attached to the organic materials were found to be recovered in the solid phase with or without precipitation reagents and showed no transfer to gas phase.

Appreciable yield of $6.2 \%$ in the thermal neutron fission leads to the formation of technetium-99 with long-lived halflife $\left(t_{1 / 2}=2.1 \times 10^{5} \mathrm{y}\right)$. The LLW also contains the technetium, which is known to have oxidation states from 0 to VII and shows variety of chemical properties including sublimation of $\mathrm{Tc}_{2} \mathrm{O}_{7}$ above $584 \mathrm{~K}^{4}{ }^{4}$ For the decomposition of LLW by the SCW method, the distribution behavior of technetium is to be clarified. In this study, distribution of technetium after supercritical water reaction among solid, liquid and gas phases were determined. The distribution behavior was discussed concerning with differences (i) between SCW reaction with ruthenium oxide $\left(\mathrm{RuO}_{2}\right)$ and with hydrogen peroxide $\left(\mathrm{H}_{2} \mathrm{O}_{2}\right)$, (ii) with or without its carrier and (iii) between technetium and alkaline metal. In addition, adsorption of technetium on surface of various metal materials, which are candidates for reactor materials, during the SCW reactions were discussed.

*Corresponding author. E-mail: yamamura@imr.tohoku.ac.jp. FAX: +81-22-215-2121.

\section{Experimental}

Technetium-95m was produced by ${ }^{93} \mathrm{Nb}(\alpha, 2 \mathrm{n}){ }^{95 \mathrm{~m}} \mathrm{Tc}$ reaction at Cyclotron and Radioisotope Center of Tohoku University and purified by sublimation, followed by dissolution in water to prepare $\mathrm{HTcO}_{4}$. $\mathrm{NH}_{4}{ }^{99} \mathrm{TcO}_{4}$, possessed by Faculty of Science, Tohoku University, was used as a carrier. Ruthenium(IV) oxide (purity: $>99.9 \%$ ) and granular polyethylene (medium density) were purchased from Kishida Chemical Co., Japan and Aldrich Chemical Company, Inc., U.S.A., respectively, and used without further treatment.

A batchwise reactor with $10 \mathrm{~mL}$ capacity made of Hastelloy C-22 was used. A small portion of an aqueous solution including about $1 \mathrm{mg}$ of technetium, three pieces of metal plates (SUS304, Hastelloy C22, Inconel 625, $5 \times 10 \times 1 \mathrm{~mm}$ size, polished with \#2000), water and either of oxidant $\left(\mathrm{H}_{2} \mathrm{O}_{2}\right)$ or reductant $\left(\mathrm{RuO}_{2}\right.$ and $150 \mathrm{mg}$ of granular polyethylene) were loaded into the reactor and the supercritical reaction under the condition of "723 K-43 MPa-30 min." was carried out. After cooled off to room temperature, distribution coefficient was determined by measurement of $\gamma$-ray spectra of three phases separated (solid, liquid and gas) and metal pieces. Cesium solution with a tracer of ${ }^{137} \mathrm{Cs}$ was used for a reference of the behavior.

The radioactivity of ${ }^{95 \mathrm{~m}} \mathrm{Tc}$ was determined from the areas of peak at $204.11 \mathrm{keV}$ by using a $\gamma$-ray spectrometer (GEM28185-P, ORTEC Inc., USA). The distribution of their radioactivity in solid, liquid and gas phases was determined as given by

$$
D_{\text {phase }}=\frac{A_{\text {phase }}}{A_{\mathrm{T}}}
$$

where $D_{\text {phase }}$ designates the distribution ratio, $A_{\mathrm{T}}$ and $A_{\text {phase }}$ are radioactivity of sample before the supercritical-water reaction and radioactivity of each phase respectively, and the subscription phase is "sol", "liq" or "gas", referring to the solid phase, the liquid phase and the gas phase, respectively. The radioac- 
tivity of each radioisotope in a sample was extrapolated to the time point at which the radioactivity, loaded into the supercritical-water reactor, was measured before the supercritical-water reaction. The typical time periods required for the $\gamma$-ray measurements were 30 minutes for the solid phase, 3 hours for the liquid phase and 48 hours for the gas phase.

\section{Results and Discussion}

3.1. Preliminary experiment. In a preliminary experiment for examining reaction of technetium with supercritical water, only around $10 \%$ of technetium was found in a recovery (liquid phase and solid phase) when $\mathrm{SCW}-\mathrm{RuO}_{2}$ reaction including technetium was performed (Figure 1, 1st reaction). Technetium was not detected in recovered gas phase at all. By measuring $\gamma$ rays from inside of the hastelloy reactor, appreciable quantity of technetium was found in the reactor, in spite that inside walls were rinsed many times with water after $\mathrm{SCW}-\mathrm{RuO}_{2}$ reaction. In order to remove adsorbed technetium, $\mathrm{SCW}-\mathrm{H}_{2} \mathrm{O}_{2}$ reaction without technetium was examined and more than $80 \%$ of technetium to loaded quantity was recovered (Figure 1, 2nd reaction). According to these results, $\mathrm{SCW}-\mathrm{H}_{2} \mathrm{O}_{2}$ reaction effectively removes technetium adsorbed inside the hastelloy reactor, whereas SCW- $\mathrm{RuO}_{2}$ reaction has not show such ability. Actually, SCW- $\mathrm{RuO}_{2}$ reaction was examined again in 3rd reaction, but only less than $1 \%$ of technetium was recovered, which is in clear contrast to further $\mathrm{SCW}-\mathrm{H}_{2} \mathrm{O}_{2}$ reaction done in 4-7 reactions which remove technetium significantly. Since in the 5 th reaction by $\mathrm{SCW}-\mathrm{H}_{2} \mathrm{O}_{2}$ yield only less than $2 \%$ of technetium, we decided that 5 times of $\mathrm{SCW}-\mathrm{H}_{2} \mathrm{O}_{2}$ reaction should be done for finishing a supercritical water experiment with technetium.

\subsection{Distribution of technetium with or without carrier}

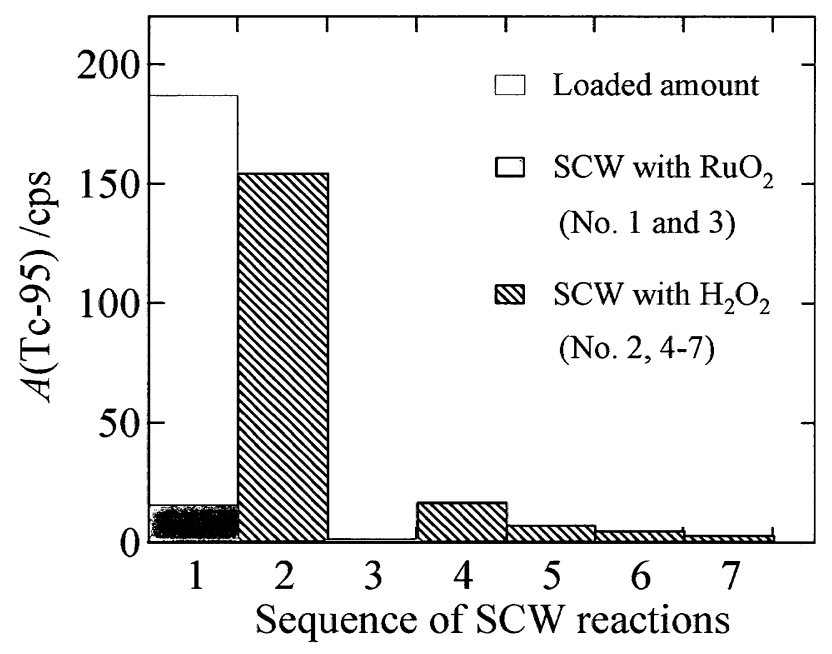

Figure 1. Activity of Tc-95 loaded and found in recovered samples obtained by supercritical water with $\mathrm{RuO}_{2}$ and polypropylene (No. 1 and 3) or with $\mathrm{H}_{2} \mathrm{O}_{2}$ (No. 2 and 4-7). and/or precipitating agent. Amount of technetium found in the solid, liquid and gas phases recovered after supercritical water reaction (i.e. not including the recovery of washings by $\mathrm{SCW}$ with $\mathrm{H}_{2} \mathrm{O}_{2}$ reaction to remove adsorbed technetium inside of the reactor) are indicated in ratio $D$ in Table 1. Both in $\mathrm{H}_{2} \mathrm{O}_{2}$ and $\mathrm{RuO}_{2}$ methods, technetium does not transfer to gas phase in spite of its low boiling point but limited to solid phase. This distribution of technetium was not affected by addition of its carrier of ${ }^{99} \mathrm{Tc}$ but shifted to solid phase by addition of $\mathrm{Fe}(\mathrm{OH})_{3}$. Summarizing the results, technetium can be recovered in solid phase without transfer to gas phase.

3.3. Distribution of technetium onto metal surfaces. It is worthwhile to note that technetium shows a large tendency to be adsorbed onto metal surfaces and the adsorbed technetium should be removed by repeating washing by $\mathrm{H}_{2} \mathrm{O}_{2}$ method for the next reaction. In order to elucidate the adsorption on metal surfaces, supercritical water reactions were carried out with three types of metal materials (Table 2). Moreover, the results for technetium was compared with those for cesium, which is a member of alkaline metal ion whose character is simple ionic. Technetium was found to adsorbed onto various metal materials. Washing by SCW with $\mathrm{H}_{2} \mathrm{O}_{2}$ for 5 times is required to remove the adsorbed technetium from the reactor.

In $\mathrm{RuO}_{2}$ method technetium may be reduced to colloidal or polymeric $\mathrm{TcO}_{2}$ or $\mathrm{TcO}(\mathrm{OH})_{2}$ which has a great affinity to metal surface. ${ }^{5,6}$ The adsorbed $\mathrm{TcO}_{2}$ can be oxidized to $\mathrm{TcO}_{4}{ }^{-}$ by $\mathrm{H}_{2} \mathrm{O}_{2}$ and dissolved in solution. Effect of supercritical water with $\mathrm{RuO}_{2}$ on technetium chemistry requires further investigation.

\section{Conclusion}

Distribution of technetium after supercritical water reaction was investigated. Technetium does not transfer to gas phase in spite of its low b.p. but distributes to solid phase in SCW and $\mathrm{SCW}$ with $\mathrm{RuO}_{2}$. Furthermore, technetium was found to adsorbed on to various metal materials. Washing by SCW with $\mathrm{H}_{2} \mathrm{O}_{2}$ for 5 times is required to remove adsorbed technetium from reactor. The result of adsorption of technetium by SCW with $\mathrm{RuO}_{2}$ and the dissolution by SCW with $\mathrm{H}_{2} \mathrm{O}_{2}$ suggested that the reductive atmosphere of SCW with $\mathrm{RuO}_{2}$ may result in the formation of colloidal or polymeric $\mathrm{TcO}_{2}$ or $\mathrm{TcO}(\mathrm{OH})_{2}$ which have a great affinity to metal surface. The supercritical water process can be used for decomposition of non-flammable plastics of LLW with limiting technetium to solid and onto metal surfaces.

Acknowledgements. We would like to thank Mr. M. Takahashi of Experimental Facility for Alpha-Emitters of IMR, Tohoku University, for his kind cooperation. This work was performed at the International Research Center for Nuclear Materials Science, Institute for Materials Research, Tohoku University.

TABLE 1: Distribution of Technetium to Three Phases After Supercritical-Water Reactions

\begin{tabular}{lccccc}
\hline \multirow{2}{*}{ Reaction } & \multicolumn{2}{c}{ Carrier } & \multirow{2}{*}{$10^{2} D_{\text {sol }}^{\ddagger \dagger}$} & $10^{2} D_{\text {liq }}^{\ddagger \dagger}$ & $10^{2} D_{\text {gas }^{\ddagger}}^{\ddagger}$ \\
\cline { 2 - 4 } & Tc-99/mg & $\mathrm{Fe}(\mathrm{OH})_{3} / \mathrm{mg}$ & & $0.71(2.89)$ & 0.00 \\
$\mathrm{RuO}_{2}$ method & --- & --- & $23.75(97.11)$ & $0.64(2.74)$ & 0.00 \\
& 0.5 & --- & $22.86(97.26)$ & $0.12(0.70)$ & 0.00 \\
\hline $\mathrm{H}_{2} \mathrm{O}_{2}$ method & 0.5 & 13 & $17.30(99.30)$ & $0.63(0.72)$ & 0.00 \\
& --- & --- & $86.54(99.28)$ & 0.00 \\
\hline
\end{tabular}

${ }^{\ddagger}$ Values of $D_{\text {phase }}$ were determined according to eq 1. ${ }^{\dagger}$ Values in parentheses are calculated by $D_{\text {phase }} /\left(D_{\text {sol }}+D_{\text {liq }}+D_{\text {gas }}\right)$ 
TABLE 2: Distribution of Tc and Cs to Each Site After Supercritical-Water Reactions of Nonflammable Plastics ${ }^{\text {II }}$

\begin{tabular}{|c|c|c|c|c|c|c|c|c|c|c|}
\hline \multirow{2}{*}{ Contents } & & \multicolumn{2}{|c|}{ No reaction $^{\ddagger}$} & \multicolumn{4}{|c|}{$\mathrm{RuO}_{2}$ method } & \multicolumn{3}{|c|}{$\mathrm{H}_{2} \mathrm{O}_{2}$ method } \\
\hline & & Cs-137 & Tc-95m & Cs-137 & $\begin{array}{c}\mathrm{Cs}-137+ \\
\mathrm{CsNO}_{3} \\
\end{array}$ & Tc-95m & $\begin{array}{c}\text { Tc-95m }+ \\
\text { Tc-99 }\end{array}$ & Cs-137 & Tc-95m & $\begin{array}{c}\text { Tc-95m }+ \\
\text { Tc-99 }\end{array}$ \\
\hline \multirow{3}{*}{$\begin{array}{l}\text { Phases recovered } \\
\text { after reaction }\end{array}$} & Solid phase & $--^{\dagger}$ & $--^{\dagger}$ & 5.8 & 15.63 & 33.9 & 65.75 & 1.9 & 17.8 & 16.75 \\
\hline & Liquid phase & 83.7 & 85.5 & 64.5 & 80.29 & 0.5 & 0.76 & 80.2 & 1.5 & 23.62 \\
\hline & Gas phase & $--^{\dagger}$ & $--^{\dagger}$ & 0 & 0 & 0 & 0 & 0 & 0 & 0 \\
\hline \multirow{3}{*}{ Metal specimens } & SUS304 & 0 & 0 & 0 & & 1.9 & 1.95 & 0 & 1.2 & 1.47 \\
\hline & Hastelloy & 0 & 0 & 0 & & 7.7 & 0.93 & 0 & 3.8 & 0.62 \\
\hline & Inconel & 0 & 0 & 0 & & 1.4 & 1.38 & 0 & 0.9 & 0.71 \\
\hline \multirow{5}{*}{$\begin{array}{l}\text { Washings with } \\
\mathrm{SCW}-\mathrm{H}_{2} \mathrm{O}_{2} \text { reaction }\end{array}$} & 1st reaction & 3.1 & 4 & 6.9 & 4.17 & 22.6 & 24.12 & 12.1 & 51.8 & 28.55 \\
\hline & 2 nd reaction & 1.3 & 1.6 & 5.9 & 0.63 & 4.8 & 1.79 & 2.4 & 3.8 & 5.58 \\
\hline & 3rd reaction & --- & --- & 2.9 & 0.17 & 2.3 & 0.52 & 1.1 & 1.7 & 1.11 \\
\hline & 4 th reaction & --- & --- & 1.6 & 0.12 & 3.8 & 0.41 & 1.3 & 1.3 & 0.26 \\
\hline & 5 th reaction & --- & -- & 0.8 & & 1.4 & 0.38 & 0.5 & 0.8 & 0.51 \\
\hline \multicolumn{2}{|c|}{ Total amount recovered } & 88.1 & 91.1 & 88.4 & 101.01 & 80.3 & 97.99 & 99.5 & 84.6 & 79.18 \\
\hline
\end{tabular}

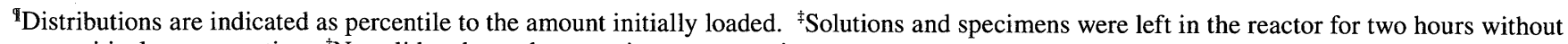
supercritical water reaction. ${ }^{\dagger}$ No solid and gas phases owing to no reaction.

\section{References}

(1) K.-C. Park and H. Tomiyasu, Chem. Commun. 694 (2003).

(2) W. Sugiyama, T. Yamamura, K. C. Park, H. Tomiyasu, I. Satoh, Y. Shiokawa, H. Okada, and Y. Sugita, J. Supercrit. Flui. 35, 240 (2005).

(3) W. Sugiyama, K.-C. Park, T. Yamamura, T. Koizumi, H. Okada, Y. Sugita, and H. Tomiyasu, J. Nucl. Sci. Technol.
42, 256 (2005).

(4) K. Schwochau, Technetium: Chemistry and Radiopharmaceutical Applications. ed. Wiley-Vch: Weinheim, 2000.

(5) S. Naito, T. Sekine, Y. Kino, and H. Kudo, Radiochim. Acta 82, 129 (1998).

(6) T. Sekine, H. Narushima, Y. Kino, H. Kudo, M. Lin, and Y. Katsumura, Radiochim. Acta 90, 611 (2002). 